\title{
Differential Magnetic Resonance Neurofeedback Modulations across Extrinsic (Visual) and Intrinsic (Default-Mode) Nodes of the Human Cortex
}

\author{
Tal Harmelech, ${ }^{1}$ Doron Friedman, ${ }^{2}$ and Rafael Malach ${ }^{1}$ \\ ${ }^{1}$ Department of Neurobiology, Weizmann Institute of Science, Rehovot 7610001, Israel and ${ }^{2}$ School of Communications, The Interdisciplinary Center, \\ Herzliya 46150, Israel
}

Previous advances in magnetic resonance imaging allow the analysis of blood oxygen level-dependent signals in real time, thus opening the possibility of feeding an index of these signals back to scanned human participants. However, it is still not known to what extent different cortical networks may differ in their sensitivity to such internally generated neurofeedback (NF). Here, we compare NF efficacy across six cortical regions including: early and high-order visual areas and the posterior parietal lobe, a prominent node of the default mode network (DMN). Our results reveal a consistent difference in NF activation across these areas. Sham controls ruled out a role of attention/arousal in these effects. These differences are suggestive of a relationship to the relative reliance on intrinsic information, moving from early visual cortex (lowest) to the DMN (highest). Interestingly, the visual parahippocampal place area showed NF activation closer to the DMN node. The results are compatible with the notion of the DMN as an intrinsically oriented system.

Key words: default mode network; imagery; self-activation; neurofeedback; real-time fMRI; visual hierarchy

\section{Introduction}

The "default mode network" (DMN) is a large-scale system that shows a consistent reduction in activity when subjects engage in externally oriented tasks (Raichle and Snyder, 2007). We and others have hypothesized that this network may in fact be specialized for intrinsically oriented functions that are detached from the immediate external environment (Gusnard et al., 2001; Golland et al., 2007; Buckner et al., 2008; Preminger et al., 2011). However, it should be noted that the specialization trend toward reliance on intrinsic information is not a categorical distinction of the DMN. For example, within the visual system, as one moves along the cortical hierarchy, there is a tendency for brain activation to be dissociated from the external physical stimulation and become closer to the perceptual inner state of the individual (Treisman and Kanwisher, 1998; O'Craven and Kanwisher, 2000; Avidan et al., 2002; Grill-Spector and Malach, 2004; Lee et al., 2007).

Thus, an important characteristic of cortical functional specialization appears to be a differential link to extrinsic versus intrinsically derived signals. Although most studies that explore this issue were based on carefully controlled stimuli and tasks, it

Received July 27, 2014; revised Dec. 22, 2014; accepted Dec. 22, 2014.

Author contributions: T.H. and R.M. designed research; T.H. performed research; D.F. contributed unpublished reagents/analytic tools; T.H. analyzed data; T.H. and R.M. wrote the paper.

This work was supported by the EU FP7 VERE project, ICORE program (ISF 51/11) grants, and the Helen and Martin Kimmel award to R.M. We thank Nahum Stern, Fanny Atar, and Dr. Edna Haran-Furman for their assistance in the imaging setup and rtfMRI data collection, and Michal Harel for helpful input.

The authors declare no competing financial interests.

Correspondence should be addressed to Rafael Malach at the above address. E-mail: rafi.malach@weizmann.ac.il.

DOI:10.1523/JNEUROSCI.3098-14.2015

Copyright $\odot 2015$ the authors $\quad 0270-6474 / 15 / 352588-08 \$ 15.00 / 0$ occurred to us that a complementary perspective could be provided by the newly introduced method of magnetic resonance (MR)-based neurofeedback (NF; MR-NF). The NF method is based on feeding a representation of brain activations back to the participants during the MR scanning (Yoo and Jolesz, 2002; Weiskopf et al., 2004b; Goebel and Linden, 2014).

Here, we hypothesize that if indeed the DMN is a network tuned to intrinsically derived information, it should be more amenable to the NF method compared to the extrinsically oriented visual system. It should be noted that this prediction is diametrically opposite to what is typically found during external stimulation, in which the DMN network shows a reduced response to external stimuli while the visual system is positively activated by such stimuli (Shulman et al., 1997; Buckner et al., 2008; Singh and Fawcett, 2008; Preminger et al., 2011). Furthermore, within the visual system proper, if indeed high-order visual areas are more dependent on the inner state of the individual, then we should expect them to also show a higher NF sensitivity compared to the more externally linked early visual areas.

To test our hypothesis, we conducted a within subject comparison of MR-NF activations across six ROIs, chosen to represent networks of presumably different links to internal information. These included a prominent node of the DMN [located in the inferior parietal lobe (IPL)] and five visual regions: early visual cortex and the high-order category selective regions lateral occipital complex (LO), extrastriate body area (EBA), fusiform face area (FFA), and parahippocampal place area (PPA) (Grill-Spector and Weiner, 2014).

Our results reveal that the DMN-related IPL showed significantly higher NF activations compared to the majority of visual areas, whereas early visual cortex showed the lowest activations. 
A

Day 1

External Localizer

\section{Day 2}

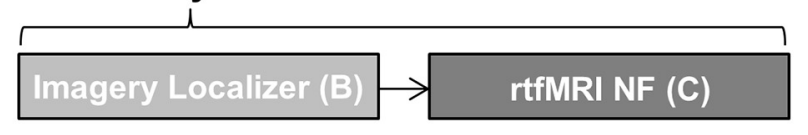

B

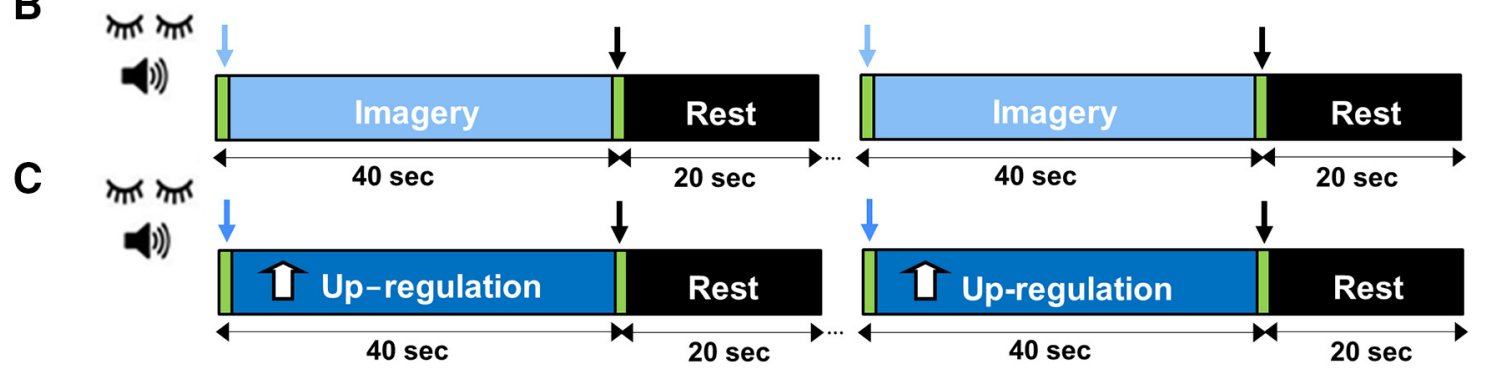

Figure 1. Experimental protocol. The experiment was held on 2 consecutive days. $A$, On the first day, subjects performed an external visual localizer task (red epoch, 9.5 min). On the following day, the subjects performed an imagery localizer task ( $5.5 \mathrm{~min}$, light gray epoch) for each of the six target ROIs, after which they underwent a real-time fMRI NF run for that ROI (dark gray epoch, 5.5 $\mathrm{min}$ ). $\boldsymbol{B}$, The imagery localizer runs consisted of five blocks of imagery (light blue epochs, $40 \mathrm{~s}$ ), with rest periods in between (black epochs, $20 \mathrm{~s}$ ). $\boldsymbol{C}$, The rtfMRI NF runs consisted of five blocks of upregulation of the target ROI (dark blue epochs, $40 \mathrm{~s}$ ), with rest periods in between (black epochs, $20 \mathrm{~s}$ ). The subjects performed both the imagery localizer runs and the NF runs with closed and covered eyes, and a brief $(<1$ s) auditory cue (green epochs, marked by arrows) symbolized the beginning of each epoch. Both the feedback and the cues of the start of each epoch were delivered via headphones. The imagery and NF runs for the different ROls were counterbalanced between the subjects.

These results highlight the usefulness of MR-NF as a new mapping tool and are compatible with the hypothesis tying the DMN network to internally related information.

\section{Materials and Methods}

Subjects. Eight healthy subjects (four females; mean age \pm SD, $28.3 \pm$ 2.06; range, 26-32) participated in the experiment. All participants were right-handed, had normal hearing and normal or corrected-to-normal vision, and provided written informed consent for their participation. The Hertzog Hospital Ethics Committee approved the experimental protocols.

Tasks and stimuli. The experiment was conducted on 2 consecutive days (Fig. 1). On the first day, subjects performed an external visual localizer task $(9.5 \mathrm{~min})$. On the following day, the subjects performed an imagery localizer task $(5.5 \mathrm{~min})$ for each of the target ROIs, after which they underwent a real-time (rt) fMRI NF run for that ROI (5.5 min). The imagery and NF runs for the different ROIs were counterbalanced between the subjects.

Localizer. To localize the visual regions of interest to be enhanced during training (see below), subjects performed two localizer tasks, one externally driven and the other internally driven. The externally driven visual localizer was a visuomotor categorization task that consisted of $9 \mathrm{~s}$ blocks of pictures from five different categories (faces, houses, bodies, tools, and textures) separated by rest periods $(6 \mathrm{~s})$. The internally driven localizer was an imagery task that consisted of blocks of imagery with intermittent rest periods (40 and $20 \mathrm{~s}$, respectively). Before the scans, subjects were given instructions for the imagery tasks that later repeated as the suggested initial cognitive strategy for the NF run. Strategies included the following: for the IPL, episodic memory or future simulation ("recall a memory from your personal past or simulate a future situation"; Andrews-Hanna et al., 2010); for the PPA, imagery of a familiar path and/or buildings; for the FFA, imagery of familiar faces (Ishai et al., 2000; O'Craven and Kanwisher, 2000); for the EBA, imagery of full bodies or body parts (Blanke et al., 2010); for the LO, imagery of tools or their manipulation (Zhang et al., 2004); and for the early visual cortex, imagery of texture patterns (Kosslyn et al., 1999). Following the localizer experiment, a target ROI was defined based on real-time analysis of the
BOLD activation during the localizer runs. The targeted ROIs were compared to those from a more conventional visual localizer experiment conducted on all of the subjects, which allowed verification of the imagery localizer using the more conventional category selectivity (Hasson et al., 2002) and DMN (Golland et al., 2007; Preminger et al., 2011) localization criteria (for details, see Definitions of ROIs, below). In cases where the imagery localizer failed to reveal a consistent activation (particularly in the case of the EVA), the ROI was based on the conventional localizer map.

Neurofeedback training. After defining the six target ROIs for each subject, the six MR-NF (Weiskopf et al., 2004b; DeCharms et al., 2005; Johnston et al., 2010) experiments were run counterbalanced within the same scanning session. The experiments were run following a similar paradigm to our previous NF study of frontal cortex activation (Harmelech et al., 2013). The NF run constituted a 5.5 min scan that included blocks of elevation and rest (Fig. 1). For the elevation condition in each experiment, participants were given an initial strategy that corresponded to the one used in the imagery localizer. However, their task was to increase the pitch of the feedback tone as much as possible, and they were encouraged to modify their strategy if that produced a higher feedback tone in the NF experiment. The subjects were also informed of the existence of a delay of $\sim 6 \mathrm{~s}$ in the feedback (resulting from the hemodynamic lag). Each block lasted $40 \mathrm{~s}$ and was followed by a $20 \mathrm{~s}$ rest period, both marked by brief $(<1 \mathrm{~s})$ auditory cues. During each run, subjects were provided with ongoing auditory feedback, a tone (2000 ms in length) every time point, whose pitch indicated the level of activity in the target ROI out of seven levels. For each time point, the baseline was calculated by extracting the minimum and maximum values from a sliding window of the last 10 time points and subtracting them to calculate the dynamic activation range. The activation range was multiplied by 1.1, in case the activation level at a given time point exceeded that range. The relative level of activity was calculated as the ratio between the average ROI value for the given time point minus the minimum value and the baseline [given time point value minus $\min / 1.1(\max$ minus $\min$ )] Both the auditory cues and the real-time feedback were provided via Confon HP-SC 01 headphones (by MR Confon). Auditory feedback was chosen after a few pilot experiments with different types of feed- 
Table 1. Talairach coordinates for the center of each NF target ROI and its volume

\begin{tabular}{|c|c|c|c|c|c|c|c|c|}
\hline \multirow[b]{2}{*}{ ROI } & \multicolumn{8}{|l|}{ Subject } \\
\hline & S1 & S2 & S3 & S4 & S5 & S6 & S7 & S8 \\
\hline \multicolumn{9}{|l|}{ IPL } \\
\hline $\begin{array}{l}\text { Talairach coordinates } \\
(X, Y, Z)\end{array}$ & $(-44,-65,23)$ & $(-46,-54,21)$ & $(-40,-72,22)$ & $(-43,-77,23)$ & $(-47,-68,24)$ & $(-42,-65,23)$ & $(-50,-61,25)$ & $(-37,-67,20)$ \\
\hline ROI volume (\# of voxels) & 6201 & 7604 & 7412 & 6615 & 9423 & 6595 & 8315 & 5805 \\
\hline \multicolumn{9}{|l|}{ PPA } \\
\hline $\begin{array}{l}\text { Talairach coordinates } \\
(X, Y, Z)\end{array}$ & \multicolumn{4}{|c|}{$(-25,-51,-4)(-26,-44,-11)(-23,-40,-10)(-28,-40,-6)$} & $(-28,-40,-8)$ & $(-21,-48,-8)$ & \multicolumn{2}{|c|}{$(-28,-54,-6)(-23,-45,-8)$} \\
\hline \multicolumn{8}{|l|}{ FFA } & 5971 \\
\hline $\begin{array}{l}\text { Talairach coordinates } \\
(X, Y, Z)\end{array}$ & $(41,-52,-17)$ & $(38,-43,-25)$ & $(43,-42,-20)$ & $(35,-45,-17)$ & $(36,-48,-18)$ & $(39,-50,-16)$ & $(34,-44,-17)$ & $(34,-51,-21)$ \\
\hline ROI volume (\# of voxels) & 4855 & 6191 & 7011 & 5427 & 6182 & 5177 & 6933 & 4905 \\
\hline \multicolumn{9}{|l|}{ EBA } \\
\hline $\begin{array}{l}\text { Talairach coordinates } \\
(X, Y, Z)\end{array}$ & $(-43,-71,4)$ & $(-48,-63,-5)$ & $(-45,-75,-4)$ & $(-42,-76,-10)$ & $(-44,-74,0)$ & $(-47,-74,-2)$ & $(-43,-77,9)$ & $(-14,-68,-2)$ \\
\hline ROI volume (\# of voxels) & 6263 & 6383 & 6533 & 6020 & 5805 & 5751 & 6376 & 6090 \\
\hline \multicolumn{9}{|c|}{ ( } \\
\hline $\begin{array}{l}\text { Talairach coordinates } \\
(X, Y, Z)\end{array}$ & $(-38,-72,-8)$ & $(-48,-64,-7)$ & $(-39,-83,-6)$ & $(-40,-77,-6)$ & $(-40,-77,-10)$ & $(-46,-71,-11)$ & $(-43,-76,7)$ & $(-25,-74,-6)$ \\
\hline ROI volume (\# of voxels) & 5724 & 6210 & 6583 & 4553 & 4311 & 4800 & 5218 & 4419 \\
\hline \multicolumn{9}{|l|}{ EV } \\
\hline $\begin{array}{l}\text { Talairach coordinates } \\
(X, Y, Z)\end{array}$ & $(8,-88,-2)$ & $(14,-88,-14)$ & $(12,-90,-14)$ & $(4,-92,-9)$ & $(10,-92,-4)$ & $(8,-93,-7)$ & $(10,-92,-4)$ & $(11,-93,-8)$ \\
\hline ROl volume (\# of voxels) & 6830 & 6472 & 7010 & 5822 & 5282 & 5129 & 7712 & 3717 \\
\hline
\end{tabular}

The cutoff significance threshold for all ROIs was $p<0.005$. The early visual cortex ROIs were based exclusively on the conventional visual localizer, whereas the other ROIs were defined as the region of overlap between the ROI defined by the conventional visual localizer and the one defined by the imagery-strategy localizer.

back (two types of visual, auditory, and bimodal) were done. The feedback that yielded the best results was the auditory feedback. The subjects also reported such auditory feedback to be less interfering with their mental strategy, while being salient enough as feedback and for monitoring.

Reports. After the imagery localizer and NF scan, the subjects were asked to rate the similarity of their thought content during the imagery localizer run and the neurofeedback on a scale of 1 to 5,1 being very similar and 5 being very different.

Sham feedback control. Six of the eight subjects participated in a sham feedback control experiment. The experiment was identical to the NF experiment, except that feedback was sampled from a different (irrelevant) ROI (V1) from the target ROI. All subjects underwent two runs, one for each of the two most successfully activated ROIs (the IPL and the PPA). In each run they were given the exact same instructions and strategy as in the NF experiment, only this time they were unknowingly given feedback according to their activity in V1.

Imaging setup. The scans were performed on a 3T Trio Magnetom Siemens scanner at the Weizmann Institute of Science, Rehovot, Israel. Three-dimensional T1-weighted anatomical images were acquired with high-resolution $1 \mathrm{~mm}$ slice thickness (3D MP-RAGE sequence; TR, 2300 $\mathrm{ms}$; TE, $2.98 \mathrm{~ms} ; 1 \times 1 \times 1 \mathrm{~mm}$ voxels). BOLD contrast was obtained with gradient echoplanar imaging sequence (TR, $2000 \mathrm{~ms}$; TE, $30 \mathrm{~ms}$; flip angle, $90^{\circ}$; FOV , $240 \mathrm{~mm}$; matrix size, $80 \times 80$; scanned volume, 35 axial slices of $4 \mathrm{~mm}$ thickness, no gap, $3 \times 3 \times 4 \mathrm{~mm}$ voxel, anterior commissure-posterior commissure).

Data analysis and preprocessing. Real-time fMRI data were analyzed with the Turbo BrainVoyager and BrainVoyager software packages (Brain Innovation) and with complementary in-house software. The first two images of each functional scan were discarded to allow for T1equilibration effects. The functional images were superimposed on $2 \mathrm{D}$ anatomic images and incorporated into the $3 \mathrm{D}$ data sets through trilinear interpolation. The cortical surface in a Talairach coordinate system $(\mathrm{Ta}-$ lairach and Tournoux, 1988) was reconstructed for each subject from the 3D MP-RAGE scan. Data were corrected for slice-dependent time shifts for each volume and 3D head motion. Motion parameters generated in the latter process were used later as nuisance regressors in the general linear model (GLM) and correlation analyses. fMRI images from the localizer tasks and the NF session were spatially smoothed with a Gaussian kernel with a full width at half maximum (FWHM) of $4 \mathrm{~mm}$. Temporal filtering of linear trends was performed to account for lowfrequency noise (e.g., scanner drift). All regressors were modeled as boxcar functions convolved with the hemodynamic response function. A hemodynamic lag of 3-6s was assumed for each subject. The analysis was performed independently for the time course of each individual voxel. After computing the coefficients for all regressors, a Student's $t$ test between coefficients of different conditions (e.g., PPA elevation vs rest) was performed. Multisubject analysis was based on a random-effects GLM. The multisubject functional maps were projected on an inflated or unfolded Talairach normalized brain. Significance levels were calculated, taking into account the minimum cluster size and the probability threshold of a false detection of any given cluster. This was accomplished by a Monte Carlo simulation (cluster-level statistical threshold estimator in BrainVoyager) using the combination of individual voxel probability thresholding ( $\alpha$ was set at 0.05 throughout). Spatial smoothing with a Gaussian kernel with a FWHM of $4 \mathrm{~mm}$ was used for individual subjects and $8 \mathrm{~mm}$ for the multisubject map.

Definitions of ROIs. All ROIs were defined individually for each subject in two stages. In the first stage (day 1 ), the regions were defined according to an external conventional visual localizer as the activated voxels located within $15 \mathrm{~mm}$ of the multisubject activity center, in the following GLM contrasts: PPA, defined using the contrast "houses > faces"; FFA, defined using the contrast "faces $>$ houses"; EBA, defined using the contrast "body parts $>$ textures"; LO, defined using the contrast "tools $>$ textures"; early visual, defined using the contrast "textures > rest"; IPL, defined as the top inactivated region.

In the second stage (day 2), the target regions for the neurofeedback were defined as the regions of overlap $(r=15 \mathrm{~mm})$ between the ROIs defined by the external conventional visual localizer and those defined by the imagery-strategy localizer (Table 1), except for cases of failure of imagery activation, where the ROI was based exclusively on the conventional visual localizer.

Statistical testing for ROI analysis. To compare the different ROI activations for the different conditions (neurofeedback vs imagery, neurofeedback vs sham, imagery vs sham), and given the relatively small sample size, nonparametric Friedman's tests were used. $P$ values were 


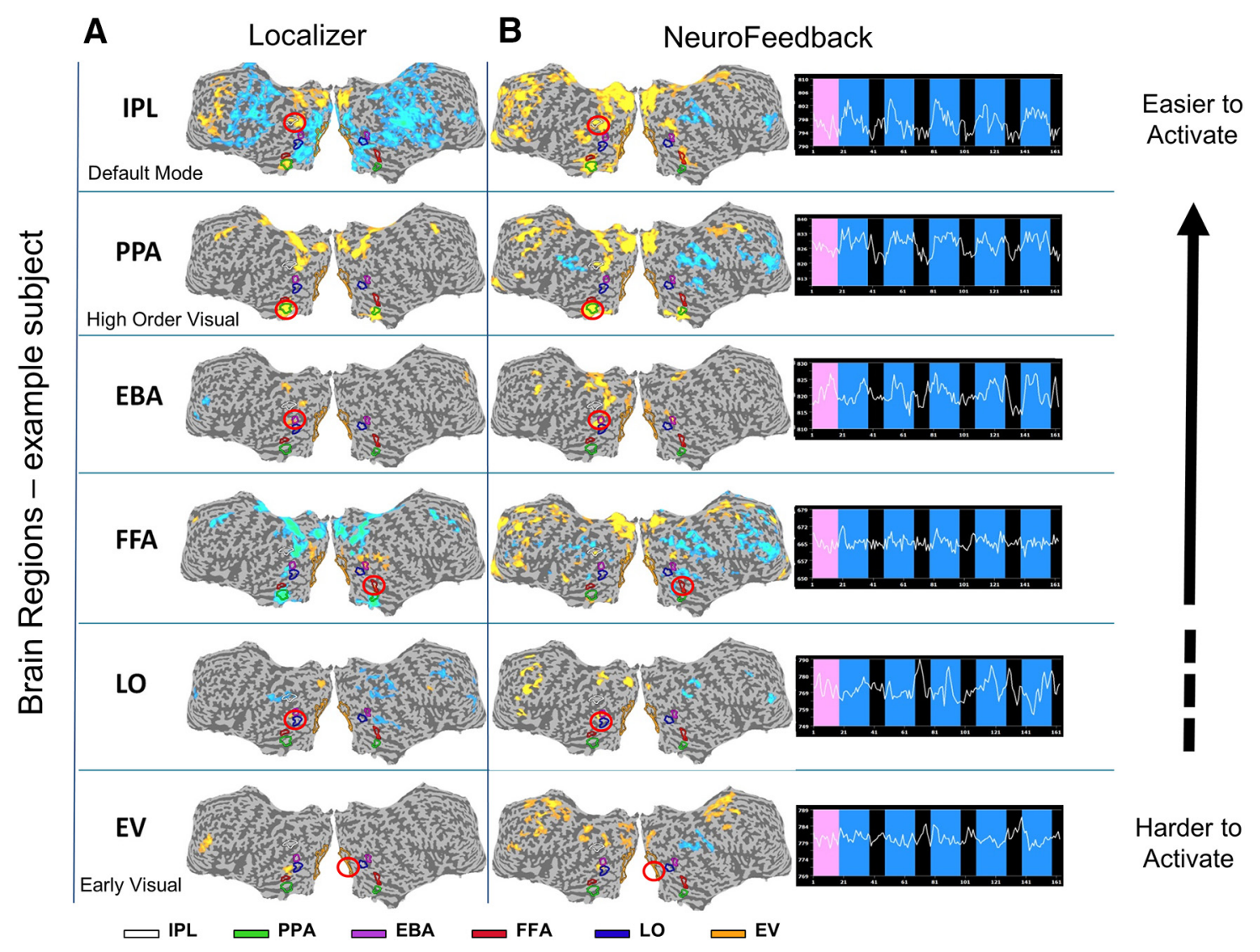

Figure 2. Differential neurofeedback modulation along the cortical hierarchy. Activation maps and time courses of the six different ROls from a representative subject are presented in descending order according to the level of success (GLM $\beta$ values) in the neurofeedback. The borders of category selective areas, early visual cortex, and DMN, defined by the conventional visual localizer experiment, are depicted in color contours (white, IPL; green, PPA; magenta, EBA; red, FFA; blue, L0; orange, early visual cortex). A red circle indicates the target regions for the NF experiments of this individual. $A$, Activation during the imagery-strategy localizer. $B$, Left, Activation during the neurofeedback. Right, time courses during the neurofeedback.

corrected for multiple comparisons using the Benjamini-Hochberg correction (Hochberg and Benjamini, 1990).

\section{Results}

After each NF experiment, participants were requested to rate the similarity of their thought content between the imagery localizer and the NF on a scale of 1 (very similar) to 5 (very different). According to the reports, the original strategy and the one the participants used for upregulation of the DMN-related IPL and the PPA were very similar (mean, $1 \pm 0$ ); for the EBA, FFA, and LO they were fairly similar $(1.4 \pm 0.18,1.4 \pm 0.18,1.9 \pm 0.22$, mean $\pm \mathrm{SE}$ ); for the early visual cortex, the strategy they reported using was somewhat different (mean, $2.5 \pm 0.19$ ).

The imagery-localizer experiment revealed differential activations associated with the different imagery and thought contents. These activations, as expected, corresponded to the well-known visual and DMN functionalities. An example of the BOLD activations produced by the six different strategies, and the locations of chosen target ROIs, are depicted on an unfolded cortex in Figure $2 A$ (localizer column) for a representative participant. The borders of category selective areas, early visual cortex, and default mode network, defined by the conventional visual localizer experiment, are depicted in color contours. The regions selected as targets for the MR-NF experiment are indicated by a red circle. As can be seen, the imagery localizer produced robust activation mainly in the IPL, EBA, and PPA. Using each of the ROIs as a target in a separate scan, participants then conducted a MR-NF experiment. The results for the NF-MR activation for the same participant are depicted in Figure $2 B$ (neurofeedback column). The maps of NF activation are shown on an unfolded cortex in the left column, and the BOLD signal time courses are shown in the right column superimposed on the protocol indicating periods of NF and rest. The maps were ordered, top to bottom, according to the level of NF activation for each ROI, as measured by the GLM $\beta$ values [IPL, $4 \pm 0.32, p<0.001$; PPA, $2.12 \pm 0.52$, $p<0.01$; EBA, $0.59 \pm 0.39$, nonsignificant (NS); FFA, $0.007 \pm$ 0.56 , NS; LO, $-0.4 \pm 0.57$, NS; early visual cortex, $-1.9 \pm 0.59$, NS]. As can be seen, the participant was quite successful in activating some of the target ROIs using the feedback signal. However, there was a striking difference in the amplitude and reliability of these activations across ROIs. In particular, the DMN IPL showed the highest activation, whereas early visual cortex showed essentially no NF activation.

This striking differential activation was consistent across participants. Figure 3 depicts summary group results, showing averaged event-related BOLD activation $(A)$ and averaged activation (GLM $\beta$ values; $B$ ). As can be seen, again the IPL DMN region showed the highest NF activation, which was significantly higher than in the visual regions. High-order visual regions (except for the LO) showed significantly higher activations than early visual cortex. Interestingly, the place-related PPA, located near the medial temporal lobe, showed a significantly higher NF activation compared to the FFA, EBA, and LO regions. Also noteworthy is the observation that the NF was a significantly more effective "activator" than the imagery strategy by itself $(p<0.05$ for all 
A

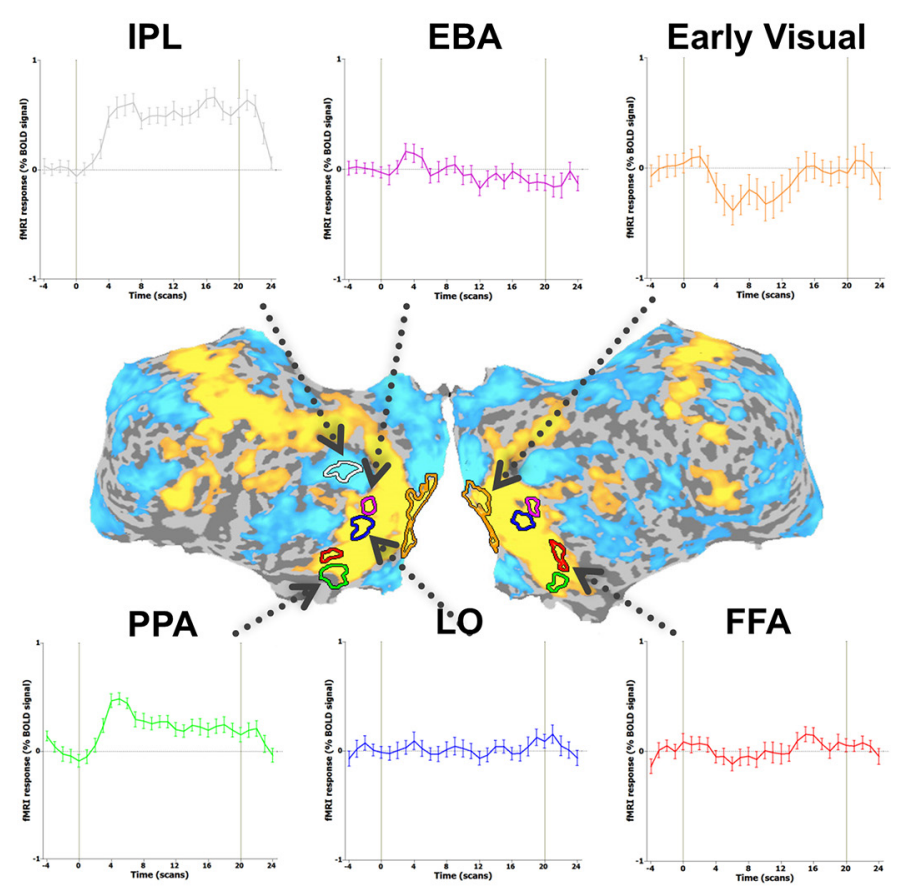

B

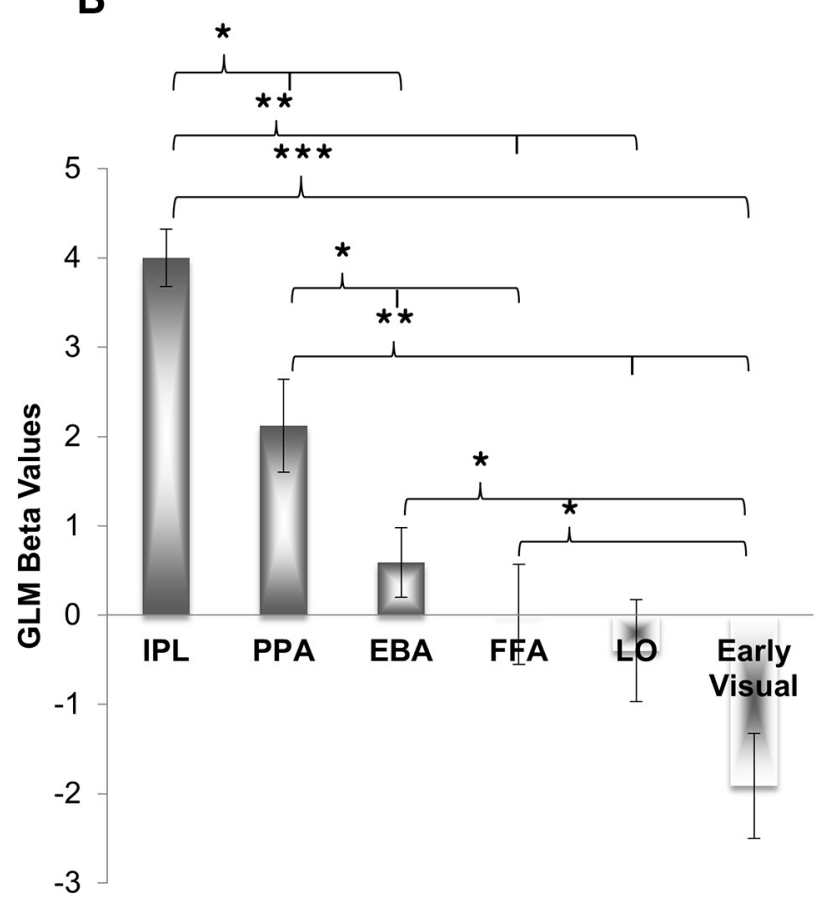

Figure 3. ROI and time course analysis during the neurofeedback along the cortical hierarchy. $A$, Averaged time courses of the NF upregulation block in the six different group-level ROIs, marked by contours on unfolded brain showing the external visual localizer activation (gray, IPL; green, PPA; magenta, EBA; red, FFA; blue, L0; orange, early visual cortex). B, Average success (GLM $\beta$ values) in the NF upregulation block is shown for the six different ROIs along the cortical hierarchy. Note the correspondence between the level in the cortical hierarchy and the success in upregulation during the NF. Asterisks denote statistical significance: ${ }^{*} p<0.05 ;{ }^{* *} p<0.01 ;{ }^{* * *} p<0.005$.

ROIs, except for LO and early visual cortex). We ran a sham feedback control (see Materials and Methods) on six of the same subjects that participated in the NF experiment. The results showed significantly lower activation levels compared to the NF (IPL, $1.9 \pm 0.44, p<0.05$; PPA, $1.28 \pm 0.25, p<0.05$ ). Furthermore, comparing the sham to the imagery strategy failed to show a significant difference (IPL, $p=0.7$; PPA, $p=0.6$ ).

\section{Discussion}

Our results reveal a striking differentiation in the ability of participants to use NF signals to activate different cortical areas. Specifically, subjects showed significantly higher NF activations of the IPL (a DMN node) than regions in the visual cortex. In contrast, subjects were largely unsuccessful in using NF to activate early visual cortex. Category selective visual areas showed a mild level of NF activation, with the intriguing exception of the PPA (Figs. 2, 3).

It could be argued that the enhanced activation we found during the NF was not a result of the feedback proper, but a more general effect, for example, a greater arousal and motivation of the participants when undergoing the NF procedure compared to simple imagery. However, our sham control, in which participants were given a "wrong" feedback, i.e., derived from a different ROI (V1), argues against this interpretation. Thus, we show a significantly weaker activation in the sham compared to the true NF procedure. Furthermore, the activation during the sham was similar to the imagery condition, indicating that, in this case, participants could not use the feedback signal to enhance the activation. Thus, we believe that the significantly higher activations the NF produced compared to the imagery strategy by itself were not due to enhanced motivation or attention (which are also present during the sham condition), but rather due to the neurofeedback itself.
It could be argued that the stronger activation in the DMN and PPA is due to the better ability of participants to choose an optimal strategy for these areas compared to, e.g., early visual cortex. Indeed, one has a clear introspective intuition that it is easier to think about an episodic memory than to imagine a complex visual texture. However, it is important to distinguish between the apparent ease in conjuring a self-generated image from the objective information we have about the optimal stimuli for an area. For example, in a NF experiment targeting olfactory representations, one may be well informed about the fact that the optimal strategy for this task should be imagining different smells, yet fail in performing the NF experiment since olfactory imagery is notoriously difficult to achieve (Stevenson and Case, 2005). Such discrepancy between objective information and subjective performance may actually be a reflection of the present findings; i.e., subjectively, it is far easier to self-activate the DMN compared to early visual cortex. However, objectively, our knowledge of the optimal stimuli that drive area V1 is undoubtedly more certain than that of the currently debated involvement of the DMN in memory function (Hinds et al., 2013). Furthermore, our knowledge of the face selectivity of the FFA is quite likely more detailed, given the extensive literature, compared to the PPA, yet the ability of subjects to self-activate the latter was far superior to the former, again matching an introspective feeling that it is more difficult to conjure up vivid faces than to remember topographical information.

\section{Differential activation within the visual system}

Regarding differential effects within high-order visual areas, the main difference we found was a preferential activation of the PPA compared to the other areas (EBA, FFA, and LO; see Results; Fig. 3). The reason for the preferential activation of the PPA is intriguing, but not fully clarified yet. One possibility is that the PPA may 
in fact be a system that has closer functional links to memory systems. The PPA is anatomically closer to medial temporal lobe structures whose link to DMN functionality has been suggested in previous work (Kahn et al., 2008). Furthermore, functional properties such as selectivity for topographical representations (Kanwisher et al., 1997) and selectivity to associative networks (Bar and Aminoff, 2003) may also be compatible with such tighter links to medial temporal lobe and DMN structures. An alternative possibility may be related to the fact that in ecological daily life, the need to self-activate topographical representations (for example, in the course of planning a navigation route) may be more adaptive than the need to conjure faces. Further research is needed to clarify this finding. Another significant result observed was the failure of subjects to use NF to activate early visual cortex. This reduced ability is in line with our overall hypothesis that the success of NF activation reflects the cortical specialization for processing internally generated information compared to externally derived information. However, it is important to emphasize that our results certainly cannot be taken as evidence against top-down effects in early visual cortex (Brefczynski and DeYoe, 1999; Gandhi et al., 1999; Davidesco et al., 2013). Our results do not rule out such influences, but rather suggest that they play a relatively minor role in NF-based activations.

\section{Potential translational impact}

It should be noted that besides adding a new functional distinction to mapping of cortical networks, our results have potential translational impact. There has been a growing interest in using self-generated brain activation as a communication tool for paralyzed individuals such as "locked-in" patients (Laureys et al., 2005; Owen et al., 2006), or even to control devices in experimental brain-machine interface (BMI) paradigms (Cohen et al., 2014). Such approaches are critically dependent on the ability of the patients to self-activate their cortical areas. From this perspective, our study highlights the DMN and PPA regions as optimal candidates for such communication and BMI strategies. Furthermore, the paradigm illustrated in the present work, of comparing NF activation across a large number of cortical areas, could be extended to provide a comprehensive NFbased activation "atlas" that could serve as an important tool for optimizing the use of self-induced brain activation for communication purposes.

\section{Relation to previous MR-NF research}

Although the MR-NF method is fairly new, a number of studies have applied it in the human cortex. Target areas were selected on the basis of either anatomical [e.g., anterior cingulate (Weiskopf et al., 2003), anterior insula (Caria et al., 2007), inferior frontal gyrus (Rota et al., 2009)] or functional (e.g., motor and visual imagery; Yoo and Jolesz, 2002; Weiskopf et al., 2004a) criteria. This method was applied and shown to produce strong activations resulting in significant brain-behavior changes in chronic pain patients (deCharms et al., 2005), emotion regulation (Johnston et al., 2010; Linden et al., 2012), motor control and Parkinson's disease (Goebel et al., 2010; Subramanian et al., 2011), and visual perceptual learning (Shibata et al., 2011; Scharnowski et al., 2012). However, to the best of our knowledge, no systematic comparison of the effectiveness of NF activations across several cortical areas has been reported so far. It should be noted that although we show that some brain regions can be self-regulated more than others in a single NF session, it re- mains an open issue whether these results pertain also to multiple sessions.

Two important aspects should be considered when comparing our results to previous studies. First, whereas our NF approach revealed a particularly weak NF regulation in area $\mathrm{V} 1$, two previous studies demonstrated NF training effects in V1 (Shibata et al., 2011; Scharnowski et al., 2012). A consistent difference between our study and these reports relates to the participants' attempt to use an explicit conscious strategy to activate V1. In the studies by Shibata et al. (2011) and Scharnowski et al. (2012) it appears that the NF signal may have exerted a direct influence on the training procedure, in absence of a concrete awareness of the participants about the training targets. These results raise the intriguing possibility that in areas that are less directly accessible to self-related representations, such as V1, network plasticity may be mediated via direct reward associations of which the participants are not aware.

A second important aspect to note is that, at least for V1, a NF approach based on multivariate decoding, may provide a superior performance (Shibata et al., 2011). This raises the possibility that a multivariate decoding that is less susceptible to feedback noise could possibly lead to a different sensitivity profile in our study. This possibility cannot be ruled out at present, and future studies using multivariate mapping across a range of cortical areas should resolve this issue.

\section{Relation to imagery}

One can envision the MR-NF approach as an optimized version of mental imagery tasks. Indeed, as our imagery localizer indicates, the imagery strategy corresponded well to the MR-NF strategy subjects used (except for the early visual cortex, probably due to lack of success in upregulation of this region). A substantial body of literature exists concerning the impact of imagery in the visual regions reported here, as well as self-generated activations of the DMN. Thus, significant activations of the FFA and PPA were reported to be associated with imagining faces and places, respectively (Ishai et al., 2000; O'Craven and Kanwisher, 2000; Soddu et al., 2009). Similarly, activations in LO have been demonstrated to be associated with imagery of tool use and objects (Zhang et al., 2004; Konkle and Oliva, 2012). Activations in the EBA were found in imagery of full and upper human bodies (Blanke et al., 2010) and imagery of tool use (Tomasino et al., 2012). However, to the best of our knowledge, none of these studies compared the magnitude of activations across these areas. An interesting issue concerns imagery effects in area V1. Although the robustness of such activations have been debated (Roland and Gulyas, 1994; Kosslyn and Thompson, 2003; Pylyshyn, 2003), previously, more sensitive approaches using multivariate classifier approaches appear to show informative signals related to imagery content in early visual cortex (Kamitani and Tong, 2005; Slotnick et al., 2005). However, again, the levels of activations were not compared to other visual cortical areas. Finally, despite the difficulty in activating the DMN above resting baseline using external stimuli, the application of "stimulus-free" paradigms, in which participants self-activate the DMN, was shown to result in robust and maintained activations (Preminger et al., 2011; Kucyi and Davis, 2014). Similarly, we showed in a previous study that the anterior cingulate cortex, which may possess functional links to the DMN (Damoiseaux et al., 2006; Park et al., 2012), can be robustly and consistently activated during NF, even leading to long-term restructuring of its spontaneous (restingstate) connectivity (Harmelech et al., 2013). 


\section{References}

Andrews-Hanna JR, Reidler JS, Sepulcre J, Poulin R, Buckner RL (2010) Functional-anatomic fractionation of the brain's default network. Neuron 65:550-562. CrossRef Medline

Avidan G, Harel M, Hendler T, Ben-Bashat D, Zohary E, Malach R (2002) Contrast sensitivity in human visual areas and its relationship to object recognition. J Neurophysiol 87:3102-3116. Medline

Bar M, Aminoff E (2003) Cortical analysis of visual context. Neuron 38: 347-358. CrossRef Medline

Blanke O, Ionta S, Fornari E, Mohr C, Maeder P (2010) Mental imagery for full and upper human bodies: common right hemisphere activations and distinct extrastriate activations. Brain Topogr 23:321-332. CrossRef Medline

Brefczynski JA, DeYoe EA (1999) A physiological correlate of the 'spotlight' of visual attention. Nat Neurosci 2:370-374. CrossRef Medline

Buckner RL, Andrews-Hanna JR, Schacter DL (2008) The brain's default network. Ann N Y Acad Sci 1124:1-38. CrossRef

Caria A, Veit R, Sitaram R, Lotze M, Weiskopf N, Grodd W, Birbaumer N (2007) Regulation of anterior insular cortex activity using real-time fMRI. Neuroimage 35:1238-1246. CrossRef Medline

Cohen O, Koppel M, Malach R, Friedman D (2014) Controlling an avatar by thought using real-time fMRI. J Neural Eng 11:035006. CrossRef

Damoiseaux JS, Rombouts SA, Barkhof F, Scheltens P, Stam CJ, Smith SM, Beckmann CF (2006) Consistent resting-state networks across healthy subjects. Proc Natl Acad Sci U S A 103:13848-13853. CrossRef Medline

Davidesco I, Harel M, Ramot M, Kramer U, Kipervasser S, Andelman F, Neufeld MY, Goelman G, Fried I, Malach R (2013) Spatial and object-based attention modulates broadband high-frequency responses across the human visual cortical hierarchy. J Neurosci 33: 1228-1240. CrossRef

deCharms RC, Maeda F, Glover GH, Ludlow D, Pauly JM, Soneji D, Gabrieli JD, Mackey SC (2005) Control over brain activation and pain learned by using real-time functional MRI. Proc Natl Acad Sci U S A 102:18626-18631. CrossRef Medline

Gandhi SP, Heeger DJ, Boynton GM (1999) Spatial attention affects brain activity in human primary visual cortex. Proc Natl Acad Sci U S A 96: 3314-3319. CrossRef Medline

Goebel R, Zilverstand A, Sorger B (2010) Real-time fMRI-based braincomputer interfacing for neurofeedback therapy and compensation of lost motor functions. Imaging Med 2:407-415. CrossRef

Goebel R, Linden D (2014) Neurofeedback with real-time functional MRI. In: MRI in psychiatry, pp 35-46. Berlin: Springer.

Golland Y, Bentin S, Gelbard H, Benjamini Y, Heller R, Nir Y, Hasson U, Malach R (2007) Extrinsic and intrinsic systems in the posterior cortex of the human brain revealed during natural sensory stimulation. Cereb Cortex 17:766-777. Medline

Grill-Spector K, Malach R (2004) The human visual cortex. Annu Rev Neurosci 27:649-677. CrossRef Medline

Grill-Spector K, Weiner KS (2014) The functional architecture of the ventral temporal cortex and its role in categorization. Nat Rev Neurosci 15: 536-548. CrossRef Medline

Gusnard DA, Akbudak E, Shulman GL, Raichle ME (2001) Medial prefrontal cortex and self-referential mental activity: relation to a default mode of brain function. Proc Natl Acad Sci U S A 98:4259-4264. CrossRef Medline

Harmelech T, Preminger S, Wertman E, Malach R (2013) The day-after effect: long term, Hebbian-like restructuring of resting-state fMRI patterns induced by a single epoch of cortical activation. J Neurosci 33:94889497. CrossRef

Hasson U, Levy I, Behrmann M, Hendler T, Malach R (2002) Eccentricity bias as an organizing principle for human high-order object areas. Neuron 34:479-490. CrossRef Medline

Hinds O, Thompson TW, Ghosh S, Yoo JJ, Whitfield-Gabrieli S, Triantafyllou C, Gabrieli JD (2013) Roles of default-mode network and supplementary motor area in human vigilance performance: evidence from real-time fMRI. J Neurophysiol 109:1250-1258. CrossRef

Hochberg Y, Benjamini Y (1990) More powerful procedures for multiple significance testing. Stat Med 9:811-818. Medline

Ishai A, Ungerleider LG, Haxby JV (2000) Distributed neural systems for the generation of visual images. Neuron 28:979-990. CrossRef Medline

Johnston SJ, Boehm SG, Healy D, Goebel R, Linden DE (2010) Neurofeed- back: A promising tool for the self-regulation of emotion networks. Neuroimage 49:1066-1072. CrossRef Medline

Kahn I, Andrews-Hanna JR, Vincent JL, Snyder AZ, Buckner RL (2008) Distinct cortical anatomy linked to subregions of the medial temporal lobe revealed by intrinsic functional connectivity. J Neurophysiol 100: 129-139. CrossRef

Kamitani Y, Tong F (2005) Decoding the visual and subjective contents of the human brain. Nat Neurosci 8:679-685. CrossRef Medline

Kanwisher N, McDermott J, Chun MM (1997) The fusiform face area: a module in human extrastriate cortex specialized for face perception. J Neurosci 17:4302-4311. Medline

Konkle T, Oliva A (2012) A real-world size organization of object responses in occipitotemporal cortex. Neuron 74:1114-1124. CrossRef Medline

Kosslyn SM, Thompson WL (2003) When is early visual cortex activated during visual mental imagery? Psychol Bull 129:723-746. CrossRef Medline

Kosslyn SM, Pascual-Leone A, Felician O, Camposano S, Keenan JP, Thompson WL, Ganis G, Sukel KE, Alpert NM (1999) The role of area 17 in visual imagery: convergent evidence from PET and rTMS. Science 284: 167-170. CrossRef Medline

Kucyi A, Davis KD (2014) Dynamic functional connectivity of the default mode network tracks daydreaming. Neuroimage 100:471-480. CrossRef

Laureys S, Pellas F, Van Eeckhout P, Ghorbel S, Schnakers C, Perrin F, Berré J, Faymonville ME, Pantke KH, Damas F, Lamy M, Moonen G, Goldman S (2005) The locked-in syndrome: what is it like to be conscious but paralyzed and voiceless? Prog Brain Res 150:495-511. CrossRef Medline

Lee SH, Blake R, Heeger DJ (2007) Hierarchy of cortical responses underlying binocular rivalry. Nat Neurosci 10:1048-1054. CrossRef Medline

Linden DE, Habes I, Johnston SJ, Linden S, Tatineni R, Subramanian L, Sorger B, Healy D, Goebel R (2012) Real-time self-regulation of emotion networks in patients with depression. PLoS One 7:e38115. CrossRef Medline

O'Craven KM, Kanwisher N (2000) Mental imagery of faces and places activates corresponding stimulus-specific brain regions. J Cogn Neurosci 12:1013-1023. CrossRef

Owen AM, Coleman MR, Boly M, Davis MH, Laureys S, Pickard JD (2006) Detecting awareness in the vegetative state. Science 313:1402. CrossRef Medline

Park B, Kim JI, Lee D, Jeong SO, Lee JD, Park HJ (2012) Are brain networks stable during a 24-hour period? Neuroimage 59:456-466. CrossRef Medline

Preminger S, Harmelech T, Malach R (2011) Stimulus-free thoughts induce differential activation in the human default network. Neuroimage 54: 1692-1702. CrossRef Medline

Pylyshyn Z (2003) Return of the mental image: are there really pictures in the brain? Trends Cogn Sci 7:113-118. CrossRef Medline

Raichle ME, Snyder AZ (2007) A default mode of brain function: a brief history of an evolving idea. Neuroimage 37:1083-1090; discussion 10971099. CrossRef Medline

Roland PE, Gulyás B (1994) Visual imagery and visual representation. Trends in neurosciences 17:281-287. CrossRef Medline

Rota G, Sitaram R, Veit R, Erb M, Weiskopf N, Dogil G, Birbaumer N (2009) Self-regulation of regional cortical activity using real-time fMRI: The right inferior frontal gyrus and linguistic processing. Hum Brain Mapp 30:1605-1614. CrossRef Medline

Scharnowski F, Hutton C, Josephs O, Weiskopf N, Rees G (2012) Improving Visual Perception through Neurofeedback. J Neurosci 32:17830-17841. CrossRef

Shibata K, Watanabe T, Sasaki Y, Kawato M (2011) Perceptual learning incepted by decoded fMRI neurofeedback without stimulus presentation. Science 334:1413-1415. CrossRef Medline

Shulman GL, Fiez JA, Corbetta M, Buckner RL, Miezin FM, Raichle ME, Petersen SE (1997) Common blood flow changes across visual tasks: II. Decreases in cerebral cortex. J Cogn Neurosci 9:648-663. CrossRef

Singh KD, Fawcett IP (2008) Transient and linearly graded deactivation of the human default-mode network by a visual detection task. Neuroimage 41:100-112. CrossRef Medline

Slotnick SD, Thompson WL, Kosslyn SM (2005) Visual mental imagery induces retinotopically organized activation of early visual areas. Cereb Cortex 15:1570-1583. CrossRef Medline 
Soddu A, Boly M, Nir Y, Noirhomme Q, Vanhaudenhuyse A, Demertzi A, Arzi A, Ovadia S, Stanziano M, Papa M, Laureys S, Malach R (2009) Reaching across the abyss: recent advances in functional magnetic resonance imaging and their potential relevance to disorders of consciousness. Prog Brain Res 177:261-274. CrossRef Medline

Stevenson RJ, Case TI (2005) Olfactory imagery: a review. Psychonom Bull Rev 12:244-264. CrossRef Medline

Subramanian L, Hindle JV, Johnston S, Roberts MV, Husain M, Goebel R, Linden D (2011) Real-time functional magnetic resonance imaging neurofeedback for treatment of Parkinson's disease. J Neurosci 31: 16309-16317. CrossRef

Talairach J, Tournoux P (1988) Co-planar stereotaxic atlas of the human brain: 3-dimensional proportional system: an approach to cerebral imaging. New York: Thieme.

Tomasino B, Weiss PH, Fink GR (2012) Imagined tool-use in near and far space modulates the extra-striate body area. Neuropsychologia 50:24672476. CrossRef Medline

Treisman AM, Kanwisher NG (1998) Perceiving visually presented objects: recognition, awareness, and modularity. Curr Opin Neurobiol 8:218226. CrossRef Medline
Weiskopf N, Veit R, Erb M, Mathiak K, Grodd W, Goebel R, Birbaumer N (2003) Physiological self-regulation of regional brain activity using real-time functional magnetic resonance imaging (fMRI): methodology and exemplary data. Neuroimage 19:577-586. CrossRef Medline

Weiskopf N, Mathiak K, Bock SW, Scharnowski F, Veit R, Grodd W, Goebel R, Birbaumer N (2004a) Principles of a brain-computer interface (BCI) based on real-time functional magnetic resonance imaging (fMRI). IEEE Trans Biomed Eng 51:966-970. CrossRef

Weiskopf N, Scharnowski F, Veit R, Goebel R, Birbaumer N, Mathiak K (2004b) Self-regulation of local brain activity using real-time functional magnetic resonance imaging (fMRI). J Physiol Paris 98:357-373. CrossRef

Yoo SS, Jolesz FA (2002) Functional MRI for neurofeedback: feasibility study on a hand motor task. Neuroreport 13:1377-1381. CrossRef Medline

Zhang M, Weisser VD, Stilla R, Prather S, Sathian K (2004) Multisensory cortical processing of object shape and its relation to mental imagery. Cogn Affect Behav Neurosci 4:251-259. CrossRef 